\title{
A WOMAN-CENTRED CHILDBIRTH MODEL
}

Author:

Maria S. Maputle

\section{Affiliation:}

${ }^{1}$ Department of Advanced

Nursing Sciences,

University of Venda,

South Africa

\section{Correspondence to: \\ Maria Maputle}

email:

sonto.maputle@univen.

ac.za

\section{Postal address:}

Private Bag X 5050,

Thohoyandou 0950,

South Africa

\section{Keywords:}

collaboration;

empowering; informationsharing; interdependence; mutual participation; responsibility-sharing

\section{Dates:}

Received: 19 May 2009

Accepted: 27 Oct. 2009

Published: 02 June 2010

How to cite this article:

Maputle, M.S., 2010, 'A

woman-centred childbirth

model', Health SA

Gesondheid 15(1), Art. \#450,

8 pages. DOI: $10.4102 /$

hsag.v15i1.450

\section{This article is available}

at:

http:/ /www.hsag.co.za

\section{INTRODUCTION AND OBJECTIVES}

A study of women's experiences of childbirth and of attending midwives during childbirth was undertaken in a tertiary hospital, in the Capricorn district of Limpopo Province. The purpose of the study was to determine how mothers experienced the care that they received during childbirth and how the midwives experienced the management of these mothers. The aim was to develop a 'womancentred' childbirth model that could be used to assist the attending midwives in the facilitation of mutual participation while managing mothers during childbirth by enhancing the implementation of the Batho-Pele principles (Department of Public Service and Administration 1997). These principles are listed in Table 1 .

TABLE 1

The Batho-Pele philosophy and principles integrated in woman-centered care

$\begin{array}{ll}\text { Consultation } & \begin{array}{l}\text { The Department of Public Service and Administration (1997) indicates that consultation can help } \\ \text { to foster a more participative decision-making and co-operative relationship between the providers } \\ \text { and the users of the public service. The shared decision-making and more active involvement of } \\ \text { consumers in their health care could increase consumers' perceptions of control which in turn could } \\ \text { improve health outcomes (Breemhar \& Van der Borne 2001:4; Lau 2002:373). } \\ \text { Service standards refer to the aspects of service that are most important to the users. The users } \\ \text { need to be informed about the service they are entitled to receive and about who is responsible for } \\ \text { their care (Department of Public Service and Administration 1997). } \\ \text { Service standards } \\ \text { Mothers should have access to skilled attending midwives during childbirth. Barriers to access, } \\ \text { namely, social, cultural and communicative, need to be taken into consideration. } \\ \text { Access } \\ \text { To ensure courtesy, according to the Code of Conduct for Public Servants issued by the Public } \\ \text { Servants' Commission, midwives must treat mothers as 'customers' who are entitled to receive the } \\ \text { highest standards of service. } \\ \text { Sufficient, balanced, non-judgmental and appropriate information was found to be important at } \\ \text { every stage of childbirth to enable mothers to take decisions and express their informed preferences } \\ \text { about their care (Fleissig 1993:71; Lau 2002:373). Those who felt ill-informed during childbirth } \\ \text { demonstrated an amount of anxiety caused by poor communication. Lau (2002:12) states that it } \\ \text { is evident that the level of the mother's knowledge contributes to the likelihood of participation in } \\ \text { decision-making because information often reduces uncertainty and attenuates the difficulty of } \\ \text { making the appropriate decision. }\end{array} \\ \begin{array}{l}\text { The 'White paper on transforming the public service' (Department of Public Service and } \\ \text { Administration 1997) indicates that the importance of public service delivery lies in the need to build }\end{array}\end{array}$
confidence and trust between the provider (midwife) and the user (mother). 
The objectives of the model were to:

- Facilitate mutual participation, as well as a respectful and egalitarian relationship between the mother and the attending midwife during childbirth.

- Enhance equality that embraced the principle of powersharing and responsibility.

- Strengthen partnership and collaboration in decisionmaking.

- Enhance self-esteem, self-determination and self-reliance when the mother was well informed.

- Promote interdependence.

\section{RESEARCH METHOD AND DESIGN}

A qualitative design was chosen for this project because the focus was on exploring and describing the experiences of childbirth for mothers, as well as the experiences of midwives who manage the mothers during childbirth. Babbie and Mouton (2001:79) have held the view that an exploratory method is typical when a researcher examines a new interest or when the subject of the study is relatively new.

\section{Population and sampling}

The population in this study consisted of all the mothers who were admitted to deliver their babies and the attending midwives who were providing midwifery care in the obstetric unit of one hospital in the Capricorn district, Limpopo Province. Nonprobability, convenience and purposive sampling were used in the study. Purposive sampling is a type of non-probability, which is collected from a group of respondents chosen for a specific key characteristic (Sells 1997:172).

The hospital that was selected is an obstetric referral hospital for all six districts in the Limpopo Province. The researcher selected available mothers in the first stage of labour, who met the inclusion criteria. These mothers were interviewed in the post-natal ward within 24 hours after delivery, to enable them to describe their experiences of all three stages of labour. All attending midwives who had at least two years' experience in the obstetric unit and who had agreed to participate in the study were sampled. Interviews with attending midwives were conducted by the researcher in the labour ward in a rest room (quiet place), for not more than 45 minutes and within 24 hours of conducting delivery.

In this research, the adequacy of the sample was attained when sufficient data had been collected so that saturation occurred and variation was both accounted for and understood. According to Glaser and Strauss (cited in Strauss \& Corbin 1990:188), saturation means that no new or relevant data seem to emerge regarding a category, the category development is dense and the relationship between the categories is well established. Twentyfour mothers and 12 attending midwives had been sampled when saturation was achieved.

\section{Data collection}

Approval for the study was obtained from the relevant authorities and participants. The study was conducted in obstetric (labour) and post-natal units. A pilot study had been conducted in the same context on a limited number of the participants from the same population, which included 12 mothers and six attending midwives (Burns \& Grove 2003:38). The rationale behind a pilot study is affirmed by Brink (1996:174), that is, the purpose of such is to investigate the feasibility of the proposed study and to detect the possible flaws in the data-collecting instrument.

The researcher used different data collection methods, the combination of which (triangulation) complemented one another by maximising quality of data and reducing the chance of bias (Hardon et al. 1994:152).

Data collection methods included unstructured in-depth interviews, participant observation, visual analogue scale (VAS), unstructured conversations and field notes (Savage 2000:326; Brink 1996:150-151, Hardon et al. 1994:173).

Interviews with mothers were conducted in the post-natal ward and attending midwives were interviewed in the labour ward in a rest room. The interviews were tape-recorded and comments were made about sensitive ethical issues such as maintaining confidentiality of data and preserving the anonymity of the informants, as well as using the research for its intended purpose (Creswell 1994:148). Tapes were numbered and the participants' names were not mentioned. During the interview, communication skills (for example, probing) were used to obtain the necessary information.

\section{Data analysis}

The narrative data from unstructured in-depth interviews were analysed qualitatively through the open coding method (Tesch 1990, cited in Cresswell 1994:155). An independent coder (selected for their experience in qualitative research methodology) was also requested to analyse the data according to Tesch's method independently from the researcher. The two analyses were then compared to ensure trustworthiness.

\section{ETHICAL CONSIDERATIONS}

Ethical considerations were based on the Democratic Nursing Organisation of South Africa (DENOSA) Ethical standards for nurse researchers (Democratic Nursing Organisation of South Africa 1998:2.3.2-2.3.4). The quality of the research was ensured by adhering to the highest possible standards of research through accountability and ability of executing the research process. Ethical approval was obtained from the University of Venda. Permission to access the childbirth unit was obtained from the Provincial Research Committee, Hospital Manager and the unit manager. Each participant was provided with sufficient and understandable information regarding the participation in the study. Confidentiality and anonymity was ensured by protecting participants' identity, privacy, worth and dignity. Right to self-determination was ensured by obtaining informed consent from the participants. There was no victimisation of participants who refused to participate in the research.

\section{TRUSTWORTHINESS}

The four criteria of trustworthiness, namely, credibility, dependability, transferability and applicability, as outlined in Lincoln and Guba (1985:301-318), were used to establish the trustworthiness of this study.

\section{Credibility}

The activities that increased the probability that credible findings and produced ensured truth-value through prolonged engagement, persistent observation, triangulation, referential adequacy, peer debriefing and member checks were ensured in this study.

\section{Dependability}

In this study, dependability was achieved through an inquiry audit, where an auditor (reviewer) examined the documentation of critical incidents (documents and interview notes) and products (findings, interpretations and recommendations) and attested that these were supported by data.

\section{Transferability}

Transferability was attained through thick description of research methodology: sufficiently detailed descriptions of data were collected in context and reported. Purposive sampling was used to maximise the range of specific information that could be obtained from and about the context, by purposely selecting locations and participants that differed from one another. 
TABLE 2

Conceptual model

Recipient: Mother

Agent: Attending midwife

Procedure: Mutual participation

Context

Dynamics

She is a person identified by virtue of her undergoing the childbirth process. The mother was found to be dependent on the attending midwife as was evidenced by her limited participation and responsibility-sharing during childbirth. Through the interaction that facilitated mutual participation, responsibility-sharing, collaboration and sharing of information, the mother would be enabled to participate in her care.

The attending midwife is a professional with specific skills who interacts with the mother to promote mutual participation and share information to facilitate participative decision-making, informed choices and autonomy during childbirth.

Mutual participation during childbirth is the cornerstone of woman-centred care. It is a reciprocal process that facilitates collaboration and partnership and can be achieved through appropriate childbirth education programmes.

The context was the childbirth unit of the tertiary hospital in the Capricorn district, Limpopo Province where the interaction took place between the mother and the attending midwife during childbirth.

The dynamics that would facilitate the process of mutual participation were contained in the Batho-Pele philosophy and principles. The Batho-Pele philosophy and principles seek to introduce a customer-focused approach that aims at putting pressure on systems, procedures, attitudes and behaviours within the childbirth units and reorients the attending midwives in the customer's favour, an approach which puts the people first (Department of Public Service and Administration 1997).

\section{Confirmability}

Confirmability was tested through the involvement of an experienced supervisor who, as an independent coder, analysed transcriptions and reviewed raw data, tape-recorded data, written field notes, documents and results independently. The independent coder reviewed open-coding (analysis) products, axial (synthesis) products, selective and theoretical coding materials relating to intention (proposals) and instrument development information. Doctoral committees and seminars were attended to establish the truth-value of the data.

\section{DISCUSSION OF RESULTS}

\section{Findings}

The results from the experiences of the mothers and attending midwives during childbirth revealed five themes, with their categories and subcategories. The themes were classified by number (Theme 1, Theme 2, and so on). Categories under the themes were then identified as:

- mutual participation and responsibility-sharing

- dependency and decision-making

- information-sharing and empowering autonomy and informed choices

- open communication and listening

- accommodative/non-accommodative midwifery actions

- maximising human and material infrastructure.

\section{Description of a woman-centred childbirth model Theory components}

Following the study 'Mothers' experiences of labour in a tertiary care hospital' (Maputle \& Nolte 2008) and the study 'Experiences of midwives of managing mothers during childbirth' (not discussed here), the woman-centred childbirth model was developed. The development of the woman-centred childbirth model contained the following six components, (1) goals, (2) concepts, (3) definitions, (4) relationships, (5) structures and (6) assumptions, as outlined in Chinn and Jacobs (1987:116).

\section{Concepts}

From the analysis of the data, 'woman-centred care' was identified as a major category. The process of concept analysis was conducted in order to identify the characteristics of the concept 'woman-centred care' (Maputle, unpublished).

The woman-centred childbirth model was thus developed through four phases in accordance with the objectives of the study, namely, description of the mothers' experiences of childbirth and that of attending midwives who manage the mothers during childbirth, analysis of the concept of womancentred care, model development and an evaluation phase. The concept analysis of woman-centred care gives a detailed method of concept analysis as described by Walker and Avant (2005:6384 ). The results of the concept analysis provided direction on how to promote mutual participation and responsibility-sharing between the mother and the attending midwife during childbirth (Maputle \& Nolte 2008). The identified concepts and subconcepts were classified and developed into a model within the six elements of the practice theory, as outlined by Dickoff, James and Wiedenbach's (1968:423) survey list cited by Madela-Mntla (1999:69) in Tlakula (1999:119). These elements are (1) recipient, (2) agent, (3) context, (4) procedure, (5) purpose and (6) dynamic. The relational statements derived after conceptualisation of each of the six concepts were inferred through the process of deductive analysis and synthesis. The relational statements provided the basis for the model development, which contained the six components outlined by Chinn and Jacobs (1987:116), namely, goals, concepts, definitions, relationships, structures and assumptions. The model was evaluated in accordance with Chinn and Kramer's (1995:134-135) method and refined by experts in midwifery practice and model generation.

Definitions of the concept of 'woman-centred' care were examined in detail, but are not discussed in this paper.

\section{Relationships}

A definition of a relationship was achieved by designing the relational statements according to the synthesis of the existing definition. According to Walker and Avant (1995:55), synthesis is the process and strategy that provides a mechanism for creating something new from the data that are already available. From the existing definition, the researcher synthesised a definition for woman-centred care within the context of the study. The process of synthesis as described by Walker and Avant (1995:100) was adapted for the study.

\section{Structure}

Conceptual model: Once synthesis was completed, the conceptual model was developed by utilising Dickoff, James and Wiedenbach's (1968:423) survey list, cited by MadelaMntla (1999:69) in Tlakula (1999:119). The list included agent, recipient, procedure, context dynamics and terminus or goal. The utilisation of Dickoff, James and Wiedenbach's survey list in a conceptual model is shown in Table 2.

\section{Process of the model}

The model (Figure 1) depicts that through the procedure of facilitating mutual participation integrated within the BathoPele principles (dynamics), 'woman-centred care' would be achieved. In the model, the arrows indicate this relationship. The process of providing woman-centred care during childbirth at the tertiary hospital would take place in three phases, namely:

- limited mutual participation (Dependence Phase)

- facilitation of mutual participation (Interdependence Phase)

- outcome (Independence Phase). 
The discussions of the empirical findings of mothers' experiences of childbirth and the experiences of the attending midwives who managed the mothers revealed that there were differences and similarities with regard to the following:

- mutual participation and responsibility-sharing

- information-sharing and empowering

- open communication and listening

- accommodative/non-accommodative midwifery actions employed at the hospital in the study.
Phase 1: Limited mutual participation (Dependence Phase)

Mutual participation, responsibility-sharing, decision-making and dependency: The results indicated that there was limited collaborative and interdependent interaction during childbirth. Mothers relied on professional and institutional expertise. Mothers' participation in their care was limited and they did not indicate/verbalise their preferences on arrival. Mothers would

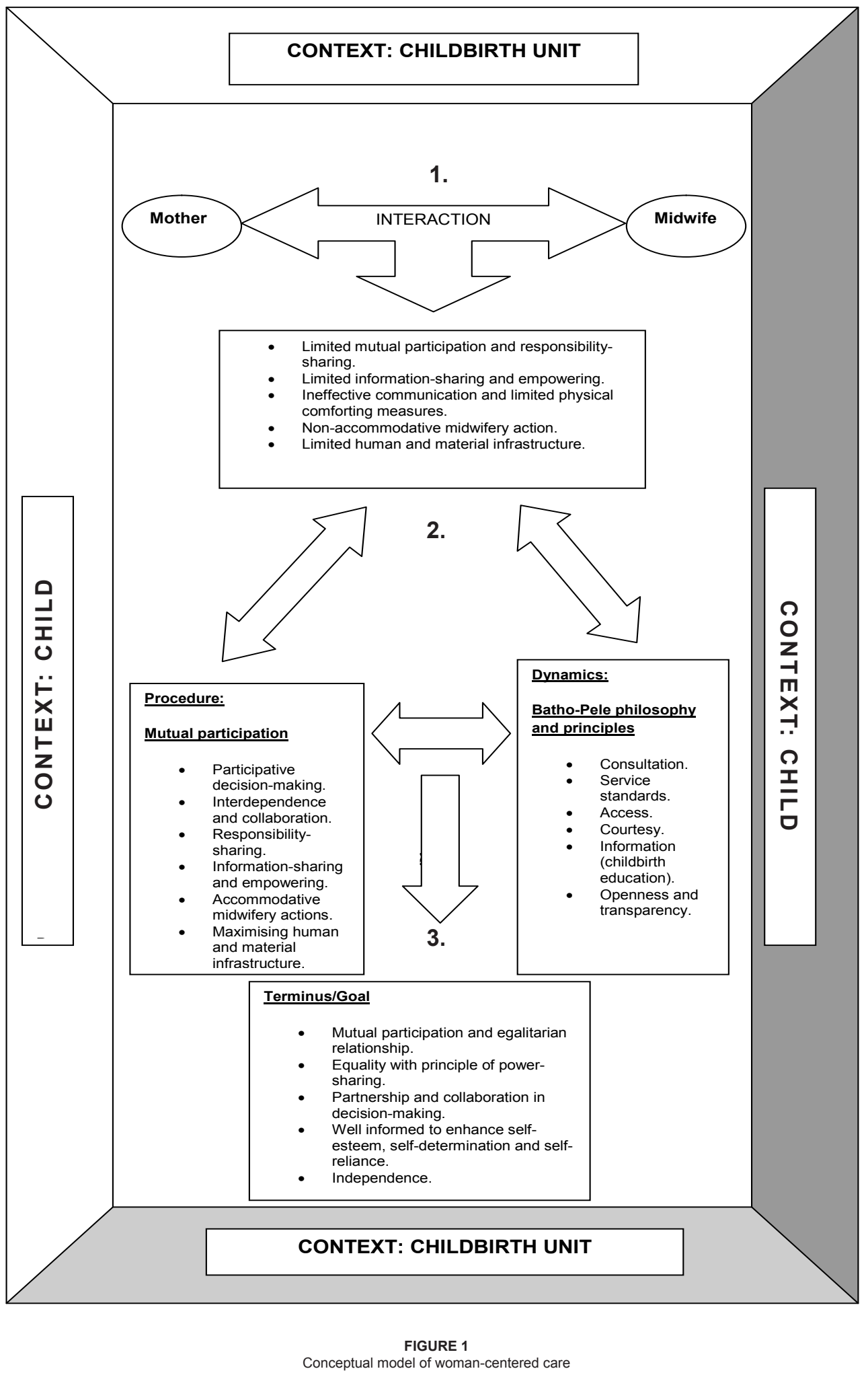


passively listen to attending midwives because they felt that midwives were trained practitioners and they knew best.

Information-sharing, empowering and autonomy: With regard to autonomy, mothers displayed limited information/ knowledge, understanding and awareness of what should be attained during childbirth. This contributed to their inability to make informed choices during childbirth. When limited opportunities were created, mothers become powerless, as evidenced by limited participation, responsibility-sharing, decision-making ability and dependency. When there was an exchange of information and knowledge between the mother and a midwife with regard to childbirth issues and available childbirth options, mothers would become empowered.

Communication, listening, trust relationship, physical comfort and emotional support: Language barriers were cited as a factor that interfered with the mothers' and midwives' interaction during childbirth and midwives displayed limited listening skills.

Accommodative midwifery actions and shortage of staff: Accommodative actions taken by midwives were to promote, support and respect the values, beliefs and preferences of mothers as long as they were not harmful to the mother and baby. Presence of a companion during childbirth was supported, although some policies and the ward environment needed to be changed to accommodate such a sanction. Both mothers and midwives cited shortage of staff as an issue of concern, since one midwife would be caring for more than two mothers at the same time. Midwives were thus not able to spend quality time with the mothers to verify their individual preferences.

\section{Phase 2: Strategies to enhance the facilitation of mutual participation (Interdependence Phase)}

Chapter 2 of the Constitution of the Republic South Africa (1996:15), through the Bill of Rights, gives citizens the right to take action against the state if they believe their constitutional rights have been infringed and to have access to information held by the state (attending midwives are agents of the state) which they need in order to participate in decision-making, exercise informed choices, and enjoy the benefits of autonomy, empowerment and independence. In line with these constitutional principles, the facilitation of mutual participation is based on the assumption that the participants have virtually the same power. They need one another and so the shared activity will be satisfactory to both; both should become active participants in the development of the nursing care plan (Pera \& Van Tonder 1996:58). To realise the Bill of Rights, the Batho-Pele principles, as a Government initiative to put people first, will be adapted in order to facilitate mutual participation between mothers and attending midwives during childbirth.

Consultation: Facilitation of consultation and participative decision-making is aimed at the establishment of a childbirth education programme, which is a client-centred process that builds confidence and self-esteem to enable parents (mothers) to take responsibility and control over their childbirth as active partners. It enables them to ask questions and seek information so that they can make informed choices and communicate effectively with the attending midwives (Nolan 1997:1201; Nolte 1998:116). The goal of childbirth education programmes is to provide mothers with useful information on childbirth in order to acquire a sound knowledge with which to challenge the rationale of some of the procedures they are expected to undergo (Laryea 1998:574). The childbirth education programme is a movement that focuses its attention on teaching women the medical definitions surrounding birth and on preparing mothers for hospital experiences.

When the mother plans to fall pregnant or when she is pregnant, she needs to consult with a midwife who will encourage her to attend the childbirth education programme. The midwife ought to create opportunities for the mother to become a partner. The techniques chosen for a particular mother will be based on a needs assessment. During consultation, the midwife is expected to respect the mothers' past experiences, plans and needs with regard to their childbirth options.

Equal partnership between a mother and her attending midwife: It is envisaged that through consultation and participative decision-making, an environment that fosters a trusting relationship will be created. Partnerships require that there should be openness and transparency. Both the mother and the attending midwife should be actively involved in the development of the health education programme. The midwife should solicit the input of mothers when developing health education materials that are relevant to the contextual needs.

Participative method: The most effective approach to use is to establish interactive groups with small numbers (Hill 1993, cited in Swain \& McNamara 1997:267).

Health education sessions and focus group discussions: Mothers should be encouraged to express their different points of view. The methods that can be used may include survey questionnaires and asking the mothers to voice their opinions about what they find useful in the childbirth education programme.

Establishment of birth plans: During the discussion sessions, mothers should be encouraged to make their birth choices and plans before labour commences. According to Brown and Lumley (1998:106), deciding on birth plans is a strategy that enhances the involvement of mothers and their families in decision-making. They further state that birth plans help to keep track of mothers' preferences when multiple caregivers are involved and that they are also a helpful vehicle for documenting and conveying to caregivers the needs and the preferences of mothers who are giving birth in an unfamiliar institution.

Principles of access: When consultation takes place, principles of access should be taken into consideration. These include the consideration of language barriers, literacy level and fear of authority, as mothers may feel intimidated while attempting to express their true opinions, if questioned by a midwife.

Personalised care: When a mother does not attend the childbirth education programme, it is proposed that individual interviews be conducted with the mother upon admission for delivery, to identify the mother's preferences, choices and the midwife's expectations.

Service standards: Service standards are commitments to provide a specified level and quality of service to individual customers at any given point in time (Department of Public Service and Administration 1997). In this study, the experiences and needs that were revealed by the consultation process have been developed into precise and measurable standards for the mother to participate in her care as follows:

- Service standards should be expressed in terms that are relevant and easily understood by mothers (mothers should be able to judge for themselves whether or not they are receiving what has been promised).

- Service standards should cover the mothers' main requirements, for example, access (language), courtesy (respect) and provision of information (education).

- Mothers must know and understand what quality of service they can expect to receive and what recourse they have if the standard is not met.

- The midwife should create opportunities to inform the mother about the results/investigations/procedures applicable to her and explain the reasons where the service has fallen short of what has been promised (communication). 
Access: The 'White paper on transforming public service delivery' (Department of Public Service and Administration 1997) states that the service delivery programme should address the need to progressively redress the disadvantages of all barriers to access. During the provision of midwifery care, barriers to access should be taken into consideration in order to facilitate mutual participation as follows:

- The attitude of the midwife should be approachable.

- The midwife should respect, encourage and support mothers' cultural and personal preferences and choices.

- The style of language and choice of words used by the midwife should be carefully considered, because words can reflect attitudes of respect or disrespect, inclusion or exclusion, judgement or acceptance, and can either ease or impede communication.

- Decision-making, autonomy, informed choices and personal control (except in situations of clear health risk) should be encouraged.

Courtesy: Midwives have a powerful effect on mothers who are giving birth. They should be aware that their power to influence impacts both positively and negatively on the mothers' childbirth experience. Mothers tend to remember the specific words and actions of midwives and their satisfaction is linked to the type of care received, feelings of personal control and accomplishment. Midwives are expected to treat all mothers with courtesy, respect and dignity during childbirth. When mothers are treated with courtesy and respect during childbirth, they participate actively in their care. The following actions could be implemented to ensure that courtesy is taken into consideration:

- Unit managers should ensure that the values and behavioural norms of the units are in line with the principles of Batho-Pele.

- The performance of midwives who are in contact with mothers during childbirth must be regularly monitored and recorded.

- Opportunities should be provided to midwives to suggest ways of improving midwifery care.

- A training programme that includes day-to-day guidance should be developed in order to ensure that Batho-Pele principles are implemented in the childbirth unit.

- It is proposed that the midwife who renders care to the mother on admission into the hospital is the one who delivers the mother's baby, in order to strengthen the trusting relationship.

Information: Sharing of information is a mutual responsibility of the midwife and the mother. The consultation process should be used to find out what mothers need to know and where and when the information can best be provided. This could be achieved through the following actions:

- The midwives should provide accurate and up-to-date information about the childbirth process. Information shared between the mother and the attending midwife is valued by mothers. Laryea (1998:572) indicates that mothers view attending classes as a type of insurance because it enables them to feel more secure.

- When providing information, individual or group teaching methods should be adopted.

- Information should be provided in the mothers' own language (access), to be relevant in order to meet the needs of the mother.

- The information should be made simple in order to maximise its comprehension and minimise any potential imposition of the attending midwife's view.

- When presenting information to mothers, an interval should elapse between the presentation of advantages and disadvantages of the proposed treatment and the patient's decision, in order for the mother to formulate and ask further questions (Marion et al. 2000:1169).

- The benefits and the risks of all the procedures need to be disclosed and explained, as well as all the options that a mother might consider. The midwives need to provide time,
- support and encouragement to the mother for exploration of various options.

- The written information should be plain and free from jargon and be supported by visual material, as this might make it easier to understand. Laryea (1998:570) supports this idea, stating that visual aids could be used, and this should include slides, films and videos to clarify the verbal information, but cultural relevance should also be considered.

- Handouts on specific topics could be supplied as a method of informing mothers during childbirth.

- Information about the available services should be made known to mothers.

- When all relevant information has been made available to the mother for the achievement of her goals, she should be guided and not directed by the midwife to share the responsibility for her care during childbirth.

The content of childbirth education programmes should also be adapted to the needs of the mother and could cover the following:

- anatomical, physiological, psychological and emotional changes during pregnancy, labour and puerperium, including changes that could affect the partner

- prevention and early detection of complications of childbirth

- management and care of minor illnesses encountered during pregnancy, labour and puerperium

- pain relief during labour

- orientation with regard to the physical surroundings of the labour ward

- orientation in the different techniques used in hospital

- orientation in the basic routines of the hospital

- all other aspects of pregnancy, labour and puerperium (adapted from Nolte 1998:120).

However, Nolan (1997:1201) points out that it is very unlikely that the childbirth education programme, as it is currently on offer, is making a significant contribution towards putting most women at the centre of their own care and enabling them to participate in decision-making about the management of their childbirth.

Openness and transparency: The 'White paper on transforming the public service' (Department of Public Service and Administration 1997) indicates that the importance of public service delivery lies in the need to build confidence and trust between the provider (midwife) and the user (mother). Pera and Van Tonder (1996:61) indicate that the most satisfactory relationship between the nurse and the patient is characterised by mutual trust and further point out that trust forms the basis of a successful and effective health care relationship.

Encourage consultation: Through consultation, the mothers will understand the type of service to be received and its accessibility, as well as feel respected and informed. Mothers will be confident and a trusting relationship will be enhanced. Mothers will feel like partners during childbirth.

Formation of partnerships: The partnership will be displayed by mutual participation and responsibility sharing, increased decision-making ability, ability to make choices and exercise autonomy, information-sharing and being empowered and forming an interdependent relationship. In the Annual Report for Service-User Involvement $(2000,2001: 1)$ it is indicated that mothers should be fully informed and involved in the plan that is tailor-made for their care.

The proposed actions would facilitate the provision of womancentred childbirth care in the Capricorn district of Limpopo Province. The results of the study by Bechell, Myers and Smith (2000:402) show that hospital units that are more patient-centred are associated with statistically significantly better outcomes than those that are less patient-centred. 


\section{Phase 3: Outcome (Independence Phase)}

There is enough evidence indicating that patients wish to collaborate with their physicians through discussion, information-sharing and mutual decision-making when they are adequately informed (Kim, Smith \& Yuego 1999:259). Womancentred care is not something that will develop overnight; it will take practice and continued childbirth and in-service education programmes to facilitate the relationship between mothers and their attending midwives. The outcome/goal of the womancentred care approach during childbirth would strive to achieve the following:

- participation that requires a mutual, egalitarian and respectful relationship

- equality that includes the principle of sharing power and responsibility

- $\quad$ negotiation between the mother and the midwife to form a partnership

- the provision of sufficient information will be a prerequisite for decision-making that enhances self-esteem and selfdetermination of the mother

- the mother and midwife would listen to each other because they engage in a dialogue to identify preferences and expectations.

Pera and Van Tonder (1996:60) refer to the final point as therapeutic reciprocity. This would be achieved through a woman-centred childbirth model aimed at facilitating mutual participation during childbirth. Pera and Van Tonder (1996:62) also state that within a partnership the attending midwives and mothers share responsibility for decision-making. Pearson et al. (1998:54) are in agreement with the notion that the attending midwife ought to operate as a partner with the mother during childbirth rather than a director of childbirth to the mother.

\section{Testing the model}

Chinn and Kramer (2008:14) indicate that empirical knowledge can be authenticated through confirmation or validation. Theoryvalidating research has a very specific meaning and would imply specific methods to be used. Chinn and Kramer (2008:262) indicate that methods are designed to ascertain how accurately the theory depicts empirical phenomena and their relationships. Theoretic statements can be translated into questions and/or hypotheses. They further indicate that no one study can test the entirety of a theory (Chinn \& Kramer 2008:262). It is therefore evident that theory-validating research usually considers a deductive approach

For this study, guidelines for critical reflection on theory from Chinn and Kramer (1995:134-135) were used to test this model. The model was further tested by midwifery experts from three South African universities. Chinn and Jacobs (1987:13) refer to this as the validation of empirical knowledge by noting and sharing convictions about the applicability of the model to the discipline, without formally testing these convictions using methods of research. The experts were to test whether the model was adequate, accurate and represented reality, for it to be assumed effective in achieving the goal if applied in midwifery practice. This was also done to ensure that the model had intersubjective certifiability. Chinn and Jacobs (1987:177180) outline the prerequisites that need to be considered before applying the model as follows:

- theory goal and practice goal relationship

- $\quad$ situational factors

- theory variables and practice variables

- nursing actions and research evidence.

These prerequisites were adapted for the study in order to make a sound judgement regarding application of the model. The midwifery experts reached consensus that the model would be of value in midwifery practice. Locally, the model was presented at a research seminar where research experts were invited to evaluate and make valuable contributions to the model.

\section{LIMITATIONS OF THE STUDY}

The study was confined to one tertiary hospital of one province, which makes it difficult to generalise. The woman-centred childbirth model also still needs to be practically implemented.

\section{RECOMMENDATIONS}

These are made with reference to all the units where there is interaction between the nursing midwife and the patient (mother). Limited participation and dependency may be experienced in all units in the hospitals wherever the patient is involved in interaction with the nurse. To be in line with the 'White paper on transforming the public service delivery' (Department of Public Service and Administration 1997), Patient Charter and the Constitution of the Republic of South Africa (1996), it is recommended that the woman-centred childbirth model be implemented. The model is aimed at enhancing the provision of woman-centred care which will facilitate mutual participation and responsibility-sharing, creation of opportunities for information-sharing and empowerment, open communication and listening, accommodative midwifery actions and maximisation of human and material infrastructure during childbirth.

\section{CONCLUSION}

This study was undertaken to construct a woman-centred childbirth model. The goal of the model was aimed at enhancing the provision of woman-centred care which would facilitate mutual participation and responsibility sharing, creation of opportunities for information sharing and empowering, open communication and listening, accommodative midwifery actions and maximising of human and material infrastructure during childbirth. The constructed model would be used to enhance the implementation of the Batho-Pele Principles.

\section{REFERENCES}

Annual report, 2000-2001, Service user involvement, viewed 11 February 2004, from http://www.slam.nhs.uk/news/ anreport/2001

Babbie, E. \& Mouton, J., 2001, The practice of social research, Oxford University Press, Cape Town.

Bechell, D., Myers, W. \& Smith, D., 2000, 'Does patient-centred care pay off?', Journal on Quality Improvement 26(7), 400-409.

Breemhar, B. \& Van der Borne, H., 1991, 'Effects of education and support for surgical patients: The role of perceived control,' Patient Education and Counselling 18, 199-210.

Brink, H.I., 1996, Fundamentals of research methodology for health care professionals, Juta \& Co. Ltd, Cape Town.

Brown, S.J. \& Lumley, J., 1998, 'Communication and decisionmaking in labour: Do birth plans make a difference?' Health Expectations 1(2), 106-116.

Burns, N. \& Grove, S.K., 2003, The practice of nursing research: conduct, critique and utilization, W.B. Saunders, n.p.

Chinn, P.L. \& Jacobs, M.K. (eds.), 1987, Theory and nursing: A systematic approach, 2nd edn., The C.V. Mosby Company, Washington DC.

Chinn, P.L. \& Kramer, M.K. (eds.), 1995, Theory and nursing: A systematic approach, 4th edn., The C.V. Mosby Company, St. Louis.

Chinn, P.L. \& Kramer, M.K. (eds.), 2008 Integrated theory and knowledge development in nursing, 7th edn., The C.V. Mosby Company, Toronto.

Creswell, J.W., 1994, Research design: Qualitative and quantitative approaches, Sage Publishers, London.

Democratic Nursing Organisation of South Africa (DENOSA) 1998, Ethical standards for nurse researchers, DENOSA, Pretoria.

Department of Public Services and Administration, 1997, 'White paper on transforming public service delivery', Government Gazette 388(18340), Government printer, Pretoria. 
Dickoff, J., James, P. \& Wiedenbach, E., 1968, 'Theory in a practice discipline. Part 1: Practice orientated theory', Nursing Research 17(5), 415-435.

Fleissig, A., 1993, 'Are women given enough information by staff during labour and delivery?', Midwifery 9, 70-75.

Hardon, A., Boonmongkon, P., Streefland, P., Tan, M.L., Hongvivatana, T., Van der Geest, S. et al., 1994, 'Qualitative data collection techniques', in Applied Health Research Manual: Anthropology of Health and Health Care, Module 17.

Kim, M.S., Smith, D.H. \& Yueguo, G., 1999, 'Medical decisionmaking and Chinese patients' self-construal', Health Communication 11(3), 249-260.

Laryea, M., 1998, 'In search of childbirth knowledge', Health Care for Women International 19, 565-574.

Lau, D.H., 2002, 'Patient empowerment - A patient-centred approach to improve care' Hong Kong Medical Journal 8(5), 372-374.

Lincoln, Y.S. \& Guba, E.G., 1985, Criteria for assessing trustworthiness of naturalistic inquiry, Sage Publications, Thousand Oaks.

Maputle, M.S. \& Nolte, A.W.G., 2008, 'Mothers' experiences of labour in a tertiary care hospital', Health SA Gesondheid 13(1), 55-62.

Marion, E.W., McCrea, H., Stringer, M. \& Murphy-Black, T., 2000, 'Personal control in pain relief during labour', Advanced Journal of Nursing 32(5), 1168-1177.

Nolan, M.L., 1997, 'Antenatal education - Where next?', Journal of Advanced Nursing 25, 1198-1204.
Nolte, A.G.W. (ed.), 1998, A textbook for midwives, J.L. van Schaik Publishers, Pretoria.

Pearson, A., Vaughan, B. \& Fitzgerald, M., 1998, Nursing models for practice, 3rd edn., Butterworth-Heinemann, Johannesburg.

Pera, S.A. \& Van Tonder, S. (eds), 1996, Ethics in nursing practice, Juta \& Co. Ltd, Cape Town.

Savage, J., 2000, 'Participative observation: Standing in the shoes of others?', Qualitative Health Research 10(3), 324.

Sells, S.P., 1997, 'Teaching ethnographic methods in social work: A model course, Journal of Social Work Education 33(1), 167184.

Strauss, A. \& Corbin J., 1990, Basics of qualitative research Grounded theory procedures \& techniques, Sage Publications, Newbury Park.

South Africa, 1996, Constitution of the Republic of South Africa [No. 108 of 1996], as amended, Government Printer, Pretoria.

Swain, R. \& McNamara, N., 1997, 'The effects of a participative programme on Irish pupils' attitudes to HIV/AIDS', Health Education Research 12(2), 267-273.

Tlakula, N.R.C., 1999, A model for facilitative interaction during conflict in a college of nursing, PhD thesis, Rand Afrikaans University, Johannesburg.

Walker, L.O. \& Avant, K.C., 1995, Strategies for theory construction in nursing, 3rd edn., Appleton \& Lange, Norwalk.

Walker, L.O. \& Avant, K.C., 2005, Strategies for theory construction in nursing, 4th edn., Pearson/Prentice Hall, Upper Saddle River. 